Title: Modern Hamelin Pied Piper: Country, Classic Rock and Metal Music

Author: Azad Kabir, MD MSPH; Raeed Kabir; Jebun Nahar, PhD.

Affiliations: Doctor Ai, LLC; 1120 Beach Blvd, Biloxi; MS 39530

Corresponding author's name and contact information (e-mail address, mailing address, phone number): Azad Kabir, MD, MSPH, ABIM; Doctor Ai, LLC; 1120 Beach Blvd, Biloxi; MS 39530; Email: azad.kabir@gmail.com; Cell: 228-342-6278

Key Words: Likes profile; music, country, classic rock, metal, income; political affiliation, red or blue, democrat, republican,

\title{
Abstract:
}

The objective of the study was to evaluate whether any certain music genre is most associated with red or blue political affiliation in the United States. The study used the red or blue political affiliation as the outcome variable. The US states most common music genres, state's average intelligence quotient (IQ), per capita income, state's percentage of evangelical population, percent of catholic population, percentage of households with gun ownership, percentage of weekly worship, and alcohol consumption as independent variables. The study found that the states' population listening to country, classic rock, and metal are six times more likely to vote for a red affiliated presidential candidate. These findings stayed significant after adjusting for income where lower income states are fifteen (15) times more likely to vote for a red presidential 
candidate compared to the states with higher per capita income. Further study is needed to evaluate whether there is a pattern of human likes (like profiles) that can determine not only political preference but also personal preferences for daily life activities.

\section{Title: Modern Hamelin Pied Piper: Country, Classic Rock and Metal Music}

\section{Introduction:}

The Economist reported that people who vote for red or blue presidential candidates tend to have similar musical tastes [1]. There are many genres of music but the most striking difference between all the genres is slow tempo music (such as country, classic and metal) versus faster steady tempo music (pop, electronic and alternative). Listening to music was found to enhance spatial-temporal reasoning in multiple previous studies $[2,3]$. That means listening to music can help improve cognitive development, and critical thinking starting from childhood. Krumhansl et al found that adolescence and the teenage years are the most important and influential time in forming musical knowledge and tastes. The study also corroborates other studies stating that people preferred the music they have been exposed to in their childhood (the music of their parents) and suggests that the preference of music develops based on the music of their home

environment. [4]. Questions remain whether listening to slow tempo music (such as country, classic and metal) versus faster steady tempo music (Pop and electronic) affects the development of spatial temporal reasoning differently leading to differences in critical thinking such as political affiliation.

Kosinski et al found that Facebook like profiles can be used to automatically and accurately predict a range of highly sensitive personal attributes including black or white with $95 \%$ accuracy, 
male or female with $93 \%$ accuracy, gay or straight with $88 \%$ accuracy and Democrat or Republican with $85 \%$ accuracy. [5]. Recently, a former employee of data firm Cambridge Analytica went public with allegations that tens of millions of Facebook users' data were captured and used to influence the 2016 US presidential election. [6]. The company uses data modeling and psychographic profiling to predict who will be future audiences, help find what message will influence the audience, and connect with people in ways that move them to action. Apparently, Cambridge Analytica used data about people "likes" - such things as music, movies, foods, and books to develop the influence campaign. This revelation also indicates music preference possibly linked to political preference and its possible to have like patterns that sway people between different political affiliation. The current study focuses on whether certain music preferences are associated with red political affiliation in the United States.

\section{Method:}

The US most popular music genre by state was compiled from the Grizzly Rose website. [7]. The Grizzly Rose compiled the most widely representative results, the top genres in terms of live performances and the most popular musicians according to Pandora 2017 streaming numbers. Among all the music genres, those states population preferred listening to country, classical rock and metal was grouped together was coded as one (1) and rest of the country was coded as zero (0) for the purpose of the analysis. The US State's average IQ scores were obtained from the McDaniel study published in 2006 [8]. The State level per capita income for the year 2010 to 2014 was collected from the U.S. Census Bureau data [9]. The 50 US States 2016 presidential elections results data (red-blue political affiliation) were collected from the Politico website election result map [10]. The red political affiliation was coded as one and blue political affiliation was coded as 
zero for the purpose of the study. The US states average alcohol consumption in gallons [11], gun ownership percentages [12], weekly worship attendance [13], percent catholic faith [14], percent evangelical faith [15] were collected.

All the above variables were used to derive the correlation matrix and multivariate logistic regression. The forward selection method was used to find the final logistic regression model. The correlation matrix, univariate analysis, and multivariate analysis, all were conducted using the SPSS data analysis software.

\section{Results:}

A total of fifty (50) US states were considered in the data analysis. In the United States, twelve (12) states preferred listening to country music. Out of them, eighty-three (83\%) percent (10 out of 12 states) voted for a red presidential candidate in 2016. And another twelve (12) states preferred listening to classic rock music. Out of them, sixty-six (66\%) percent (8 out of 12 states) voted for a red presidential candidate in 2016. And another six (6) states preferred listening to metal music. Out of them, eighty-three (83\%) percent (5 out of 6 states) voted for a red presidential candidate in 2016. Rest of the states preferred to listen to Indie (4 out of 11 voted for red presidential candidate), electronic (1 out 1 voted blue presidential candidate), alternative ( 3 out of 5 voted for blue presidential candidate), latin ( 1 out 1 voted red presidential candidate), pop (1 out 1 voted blue presidential candidate) and rhythm and blue (1 out 1 voted blue presidential candidate).

Table 1 shows states that average IQ and states alcohol consumption have the highest correlation of $0.867(P<0.01)$ and states with higher income have higher average intelligence quotient $(I Q)$ with correlation coefficient of $0.375(\mathrm{p}<0.05)$. The average US population IQ was $100( \pm 2.71)$, and 
the average per capita income was $\$ 28,889$. However, there is no significant correlation between intelligence quotient (IQ) and choice of any music genre like country, classic rock, or metal music. The state average intelligence (IQ) is positively correlated with states income, and weekly alcohol consumption; but negatively correlated with weekly worship. Also states with higher evangelical negatively correlated with alcohol consumption, but positively correlated with weekly worships and gun ownership percentages. On the contrary, states with higher Catholics positively associated with average intelligence quotient (IQ), negatively correlated with weekly worships, gun ownerships and with less percentage of evangelicals. The red, blue political affiliation was highly correlated with those prefer country, classic rock and metal, income category, and weekly worship percentages. The state per capita income is correlated with states average intelligence quotient (IQ) but intelligence quotient (IQ) has no meaningful correlation with any music preference. 
Table 1: Correlation matrix of the variables used in the analysis: Demonstrating effect of per capita income and music preference (country, classic and metal) with red, blue political affiliation.

\begin{tabular}{|c|c|c|c|c|c|c|c|c|c|}
\hline & $\begin{array}{c}\text { Country, } \\
\text { or Classic } \\
\text { Rock or } \\
\text { Metal }\end{array}$ & $\begin{array}{l}\text { Average } \\
\text { IQ }\end{array}$ & $\begin{array}{l}\text { Income } \\
\text { Category }\end{array}$ & $\begin{array}{l}\text { Alcohol } \\
\text { (Gallon) }\end{array}$ & $\begin{array}{c}\text { Weekly } \\
\text { Worship \% }\end{array}$ & $\begin{array}{c}\text { Gun } \\
\text { Owner \% }\end{array}$ & $\begin{array}{c}\text { Evangelical } \\
\%\end{array}$ & $\begin{array}{c}\text { Catholics } \\
\%\end{array}$ & $\begin{array}{c}\text { Red, Blue } \\
(2016)\end{array}$ \\
\hline $\begin{array}{l}\text { Prefer Country, or Classic } \\
\text { rock or Metal }\end{array}$ & 1 & & & & & & & & \\
\hline Average IQ & -0.012 & 1 & & & & & & & \\
\hline Low Income Category & 0.245 & $-0.375^{* *}$ & 1 & & & & & & \\
\hline Alcohol (Gallon) & -0.124 & $0.867^{* *}$ & $-0.376^{* *}$ & 1 & & & & & \\
\hline Weekly Worship \% & $0.336^{*}$ & $-0.632^{* *}$ & 0.269 & $-0.604^{* *}$ & 1 & & & & \\
\hline Gun Ownership \% & -0.003 & -0.074 & 0.057 & 0.004 & $0.369^{* *}$ & 1 & & & \\
\hline Evangelical \% & 0.119 & $-0.538^{* *}$ & 0.14 & $-0.389^{* *}$ & $0.619^{* *}$ & $0.596^{* *}$ & 1 & & \\
\hline Catholics \% & -0.02 & $0.303^{*}$ & -0.036 & 0.197 & $-0.453^{* *}$ & $-0.286^{*}$ & $-0.638^{* *}$ & 1 & \\
\hline Red, Blue (2016) & $0.417^{* *}$ & -0.13 & $0.572^{* *}$ & -0.233 & $0.287^{*}$ & 0.09 & 0.141 & -0.048 & 1 \\
\hline
\end{tabular}

* Correlation is significant at the 0.05 level (2-tailed).

** Correlation is significant at the 0.01 level (2-tailed).

This study used all the variables in the correlation matrix in the multivariate regression model. The forward selection method was used to select the final model which is shown in (Table 2). The model showed that the state with music preference of country, classic rock and metal is approx. six times more likely to vote for a red presidential candidate. In addition, the model also found the low-income category is fifteen times more likely to be associated with red politics. All other variables were found not significant which includes states average alcohol consumption, intelligence quotient (IQ), weekly warship percentages, gun ownership, percent Catholics and Evangelicals indicating some of these variable effects possibly mediated through the income or preference of music. 
Table 2: Multivariate regression analysis demonstrating the effect of three music genres and income on red (versus blue) political affiliation ( $R$ square $\mathbf{0} \mathbf{0 . 5 1})$.

\begin{tabular}{|c|c|c|c|c|c|c|}
\hline & \multicolumn{6}{|c|}{ 95\% C.I. for OR } \\
\hline & Beta & S.E. & P-Value & $\begin{array}{l}\text { Odds } \\
\text { Ratio } \\
\text { (OR) }\end{array}$ & Lower & Upper \\
\hline Prefer Country, or Classic Rock, or Metal & 1.779 & 0.779 & 0.022 & 5.925 & 1.286 & 27.297 \\
\hline Low Income & 2.725 & 0.814 & 0.001 & 15.261 & 3.098 & 75.174 \\
\hline Constant & -1.753 & 0.686 & 0.011 & 0.173 & & \\
\hline
\end{tabular}

\section{Discussion:}

In the United States, the states that prefer listening to country, classic rock and metal music are most likely to be affiliated with red politics as if these music serves as modern Hamelin pied piper. Those who prefer to listen to country or metal music, eighty-three percent (83\%) of those states voted for a red presidential candidate. And those who prefer to listen to classic rock music, sixtysix percent (66\%) of those states voted for a red presidential candidate. The effect of music on political affiliation stayed significant after adjusting for the effect of income category (high versus low). The states with lower per capita income are fifteen times more likely to vote for a red presidential candidate than blue. The current study demonstrates a stronger effect of income (low income is associated with red politics) on political preference than music preferences indicating even those who prefer to listen to country, classic rock or metal, if the states are economically richer, they tend to vote for a blue presidential candidate. Among all these states considered as swing states in the 2020 presidential election, only Arizona (metal), Michigan (classic rock), Georgia (classic rock), Wisconsin (country) and Pennsylvania (country) flipped to 
blue political affiliation during the presidential election compared to 2016. [16]. All these states were richer compared to other states in the same music preference group.

The participants in the Cornell study reported that participants preferred the music they have been exposed to during childhood, including the music of their parents [4]. This possibly led to generations of the population in the red states who prefer country, classic rock and metal who are inherently affiliated with red political ideology and ultimately those multigenerational families living in the same state led to certain states becoming solid red or blue. Those states that are wealthier and have a high number of migrations possibly became swing states as the effect of the same type of music related political preference got diluted over time.

This study's findings raise more questions than solving the mystery of how preference of certain music genres (country, classic rock and metal) modifies spatial-temporal reasoning and influences critical thinking which leads to different political affiliation. Facebook likes data can accurately predict using the likes profile of a group of individuals whether someone black or white, male or female, gay or straight, or democrat or republican [5]. This finding also indicates people's preferences (likes) are predictable behavior. Question remains: how can the like profiles of a group of individuals predict their race, sex, and political affiliation? And what role does music play in developing that preference? Does listening to certain genres of music also impact someone's critical thinking which leads to choosing certain professional careers? Is there any pattern of likes that predisposes people to commit criminal acts? Most importantly, Cambridge Analytica whistleblower indicated they influenced the audience in ways that they could move them to action for the 2016 presidential election. Can this be replicated in other areas of social 
restructuring where society can prevent violent crimes or criminal activity based on people's likes profile and move their action in a way to prevent them from committing criminal acts? This study's surprising finding of predicting political affiliation using music preference of country, classic rock or metal open new doors to future research to understand human personal and political reasoning.

There are multiple facets of human intelligence which includes intelligence quotient (IQ), emotional intelligence (EI). Recent study showed that national wealth with an equal intelligence quotient (IQ), and emotional intelligence (EI) will remain similar if other measures of good governance are held constant [17]. However, it is possible that individual wealth can not be predicted using human capital variables (intelligence quotient and emotional intelligence) alone, and there may be a third dimension of intelligence (like profile) that determines individual professional career preferences which can lead to annual income (wealth) variability among individuals despite all having the same intelligence quotient (IQ) and emotional intelligence (E). This study indicates there may be a third intelligence dimension which determines the human preference (like) profile and may be developed from childhood with the influence of music that not only determines political preference, but also personal preference as well.

The current study used state average data instead of individual data to find predictors of red, blue political affiliation. It is possible that certain geo-political or state population data reflects a more accurate picture than individual data given that political affiliation needs a society or grouplevel participation in political process. 


\section{Conclusion:}

The study found that states with red political affiliation prefer to listen to three music genres which are country, classic rock, and metal. The effect stayed significant after adjusting for the income category where states with low per capita income tend to be associated with red political affiliation. Further study is needed to evaluate how to identify the like profiles of different groups of individuals which predisposes people to make certain personal and political decisions.

Conflict of Interest: The author has no conflict of interest to disclose.

\section{References:}

1.https://www.economist.com/graphic-detail/2019/11/16/why-obama-trump-swing-voters-

like-heavy-metal

2. Rauscher, F.H. (2003). Can music instruction affect children's cognitive development? Eric Digest. (EDO-PS-03-12) ]

3. Hetland, L. (2000). Listening to Music Enhances Spatial-Temporal Reasoning: Evidence for the "Mozart Effect". Journal of Aesthetic Education,34 (3/4), 105-148. doi:10.2307/3333640]

4. KrumhansI CL, Zupnick JA. Cascading reminiscence bumps in popular music. Psychol Sci. 2013 Oct;24(10):2057-68. doi: 10.1177/0956797613486486. Epub 2013 Sep 4. PMID: 24006129.]

5. Kosinski, M; Stillwell, D; Graepel, T; Digital records of behavior expose personal traits; (2013) Proceedings of the National Academy of Sciences; 110 (15) 5802-5805; DOI: $10.1073 /$ pnas.1218772110 
6. https://www.cnn.com/2018/04/10/health/facebook-likes-psychographics/index.html

7. https://grizzlyrose.com/most-popular-music-genre-by-state/

8. McDaniel, M. A. (2006). Estimating state IQ: Measurement challenges and preliminary correlates. Intelligence, 34(6), 607-619. doi:10.1016/j.intell.2006.08.007

9. "ACS DEMOGRAPHIC AND HOUSING ESTIMATES 2010-2014 American Community Survey 1Year Estimates". U.S. Census Bureau. Archived from the original on 2020-02-14. Retrieved 201602-12.

10. The 50 US States 2016 presidential elections results from the Politico website election result map: https://www.politico.com/2016-election/results/map/president/

11. https://worldpopulationreview.com/state-rankings/alcohol-consumption-by-state

12. Gun Ownership By State 2021 (worldpopulationreview.com)

13. List of U.S. states and territories by religiosity - Wikipedia

14. US States by Population of Catholics - WorldAtlas

15. https://www.worldatlas.com/articles/us-states-by-evangelical-protestant-population.html

16. https://www.politico.com/2020-election/results/president/

17. Kabir, R.A.; Nahar, J.; Sengar, R.; Kabir, A.A. Wealth Code Unlocked: The Combined Effect of Emotional Intelligence and Intelligence Quotient. Preprints 2021, 2021070283 (doi: 10.20944/preprints202107. 0283.v1) 